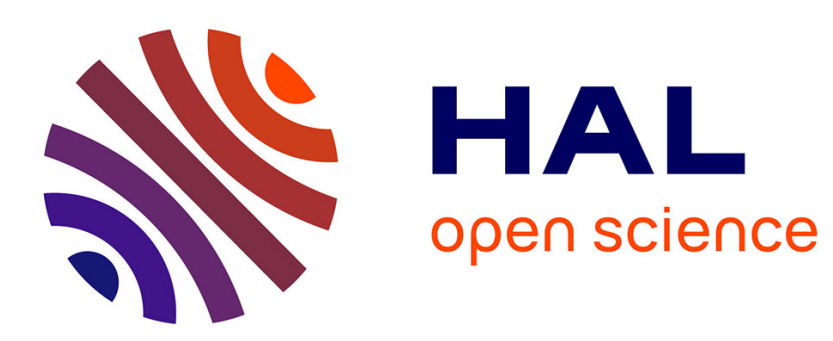

\title{
RADIATION EFFECTS.RADIATION DAMAGE IN POTASSIUM HALIDES AND ITS DEPENDENCE ON THE REACTOR SPECTRUM
}

F. Felix, M. Müller, K. Rössler

\section{- To cite this version:}

F. Felix, M. Müller, K. Rössler. RADIATION EFFECTS.RADIATION DAMAGE IN POTASSIUM HALIDES AND ITS DEPENDENCE ON THE REACTOR SPECTRUM. Journal de Physique Colloques, 1976, 37 (C7), pp.C7-481-C7-485. 10.1051/jphyscol:19767107 . jpa-00216828

\section{HAL Id: jpa-00216828 https://hal.science/jpa-00216828}

Submitted on 1 Jan 1976

HAL is a multi-disciplinary open access archive for the deposit and dissemination of scientific research documents, whether they are published or not. The documents may come from teaching and research institutions in France or abroad, or from public or private research centers.
L'archive ouverte pluridisciplinaire HAL, est destinée au dépôt et à la diffusion de documents scientifiques de niveau recherche, publiés ou non, émanant des établissements d'enseignement et de recherche français ou étrangers, des laboratoires publics ou privés. 


\title{
RADIATION DAMAGE IN POTASSIUM HALIDES AND ITS DEPENDENCE ON THE REACTOR SPECTRUM
}

\author{
F. W. FELIX, M. MÜLLER and K. RÖSSLER (*) \\ Hahn-Meitner-Institut für Kernforschung Berlin $\mathrm{GmbH}$, \\ Glienicker Str. 100, D-1000 Berlin 39, FRG \\ and \\ Institut für Chemie der Kernforschungsanlage Jülich $\mathrm{GmbH}$, Institut 1 : \\ Nuklearchemie, Postfach 1913, D-5170 Jülich, FRG
}

\begin{abstract}
Résumé. - L'étude a porté sur les dégâts par rayonnement dans des cristaux d'halogénures de potassium irradiés dans un réacteur.

Des collisions élastiques avec des neutrons rapides ont produit des défauts thermiquement stables dans du $\mathrm{KCl}$, du $\mathrm{KBr}$ et du $\mathrm{KI}$, même à proximité du point de fusion.

Aucune influence des neutrons thermiques sur le taux de production des défauts dans le KI n'a pu être mesurée.

Néanmoins, une certaine annihilation par rayonnement due à des neutrons thermiques et épithermiques a été mise en évidence dans le $\mathrm{KCl}$. Dans le $\mathrm{KBr}$ la concentration des défauts a été accrue par la présence de neutrons thermiques.

Expérimentalement, les défauts ont pu être détectés par leur impact spécifique sur la mobilité des atomes d'Argon produits par une réaction $(n, p)$ dans le $\mathrm{K}$ au cours de l'irradiation.
\end{abstract}

\begin{abstract}
The radiation damage in reactor irradiated potassium halide single crystals is investigated via specific depression of the diffusion mobility of argon atoms formed by the ${ }^{39} \mathrm{~K}(\mathrm{n}, \mathrm{p}){ }^{39} \mathrm{Ar}$ and ${ }^{41} \mathrm{~K}(\mathrm{n}, \mathrm{p})^{41} \mathrm{Ar}$ nuclear reactions. Defects which are thermally stable at temperatures near the melting point are produced by elastic collisions with fast neutrons in $\mathrm{KCl}, \mathrm{KBr}$ and KI. The influence of thermal and epithermal neutrons on kind and concentration of the defects is checked by using cadmium and boron shieldings during irradiation. Drastic differences in the Ar-diffusion behaviour indicate different primary defect structures for the three systems, the annealing properties of which may be changed by the overlapping of thermal neutron induced cascades.
\end{abstract}

Introduction. - The experiments complete earlier ones [1] on the neutron dose dependence of argon diffusion in reactor irradiated potassium halides. According to the trapping diffusion model of Norgett and Lidiard [2] this behaviour was interpreted as a result of the interaction of argon with irradiation defects. Since the concentration of these traps was proportional to the fission neutron dose, it was concluded that the defects are created in fast neutron induced collision cascades. This paper discusses new results on argon diffusion in $\mathrm{KCl}, \mathrm{KBr}$ and $\mathrm{KI}$. These experiments show that also thermal and epithermal neutrons exhibit an influence on the structure and concentration of the irradiation defects.

Experimental. - In order to obtain reproducible results, alkaline halide single crystals were cleaved with a razor blade from one larger crystal

$$
\left(1 \times 1 \times 1 \mathrm{~cm}^{3}\right)
$$

produced by Fa. Dr. Karl Korth, Kiel. The cubic crystals (edge length $0.31 \mathrm{~cm}$ ) were irradiated in the research reactor BER (HMI-Berlin) under conditions summarized in table $\mathrm{I}$. The probes radioactive ${ }^{39} \mathrm{Ar}$ and ${ }^{41} \mathrm{Ar}$, were produced via the nuclear reactions ${ }^{39} \mathrm{~K}(\mathrm{n}, \mathrm{p}){ }^{39} \mathrm{Ar}$ and ${ }^{41} \mathrm{~K}(\mathrm{n}, \mathrm{p}){ }^{41} \mathrm{Ar}$. By using a cadmium or boron absorber (Fig. 1) it was possible to reduce the fraction of thermal and epithermal neutrons by about three and one order of magnitude, respectively. This was established by measuring the activity of neutron activated ${ }^{198} \mathrm{Au}$. In the position Al near the boron and cadmium shield, cf. figure 1 , the original thermal neutron flux was depressed by a factor of about 10 .

After irradiation the gas release was measured during heating the single crystals in a closed quartz apparatus under air. Gas samples containing the ${ }^{39} \mathrm{Ar}$ released were taken after certain periods and their $\beta$-activity measured with a proportional counter. The diffusion coefficient $D$ was evaluated from the degassing function by means of Fick's second law according to the solutions of Lagerwall and Zimen [3] (for detailed information on the experimental technique and the method of evaluation, cf. $[4,5])$. In 
TABLE I

Irradiation conditions of the potassium halides

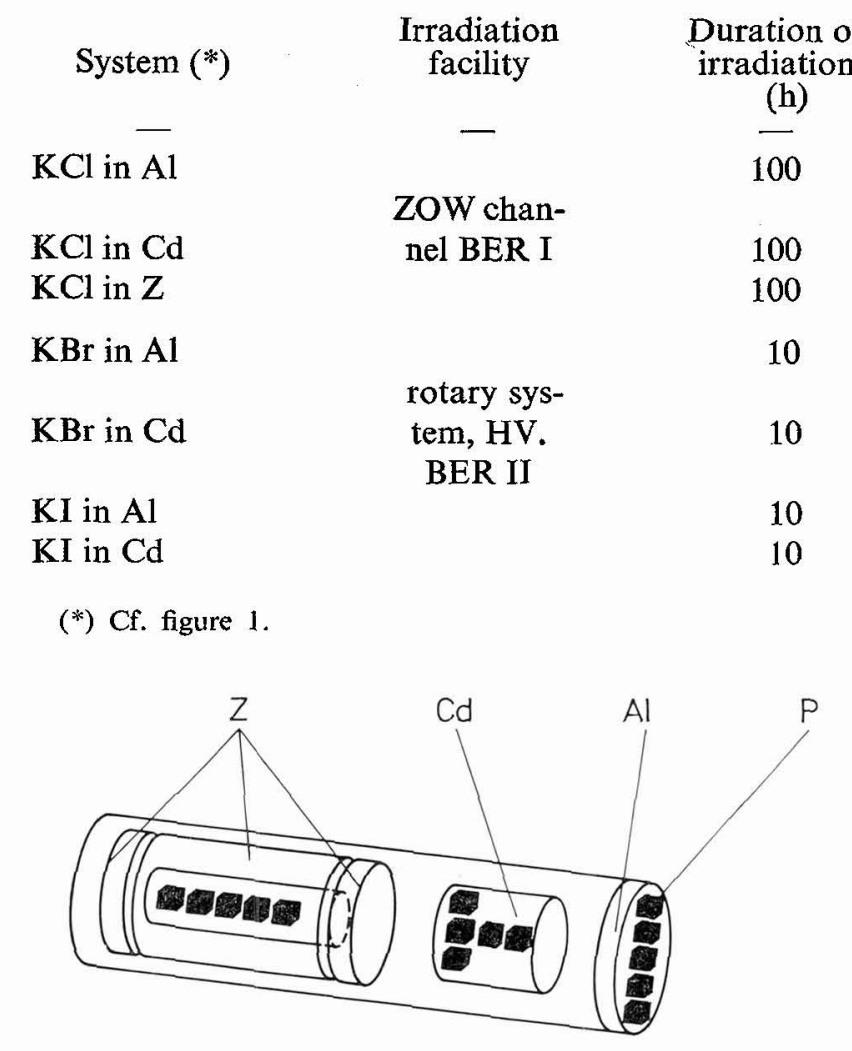

Frg. 1. - Arrangement of the samples in the irradiation capsule : $Z=$ aluminium hollow cylinder filled with boron inside a cadmium shield $; \mathrm{Cd}=$ cadmium container $; \mathrm{Al}=$ aluminium disk $; \mathbf{P}=$ samples.

some cases of nonideal diffusion [6], deviations from Fick's law were observed at the beginning of the experiment and the $D$-value was calculated from the part of the gas release function after this initial period.

Results. - Diffusion coefficients are only determined for a temperature and dose range in which interaction of irradiation defects with the rare gas can take place. Figure 2 shows an Arrhenius plot of $D$-values determined for $\mathrm{KCl}$. It can be seen that argon becomes more mobile in the presence of thermal and epithermal neutrons. The activation energies calculated with a least square fit strongly decrease with increasing thermal and epithermal neutron dose : $\Delta H_{1}=2.43 \mathrm{eV}, \Delta H_{2}=2.78 \mathrm{eV}, \Delta H_{3}=3.64 \mathrm{eV}$. This diffusion behaviour is independent of the storage time of the crystals after irradiation since the kinetics proved to be the same after 5 years. A preliminary experiment [6] under the same irradiation conditions, however without the presence of the $\mathrm{Cd}$ - and $\mathrm{B}$-shields, yielded a much higher rare gas mobility, cf. the solid line in figure 2. In $\mathrm{KBr}$ the gas diffusion behaviour also varies with the thermal neutron dose, figure 3 .

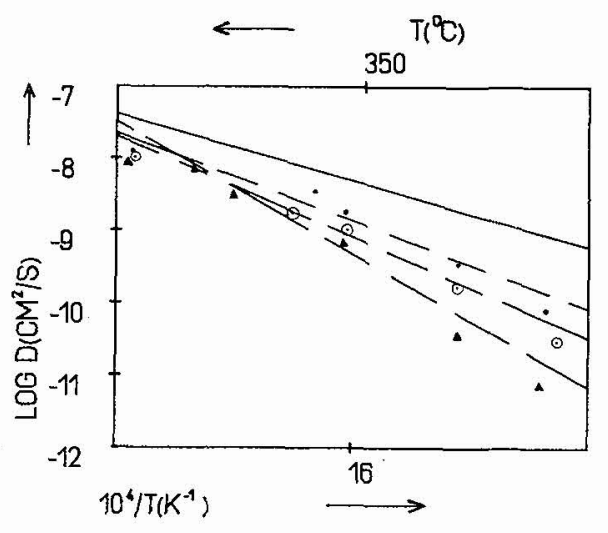

FIG. 2. - Temperature dependence of argon diffusion in $\mathrm{KCl}$ : - irradiated without shield; $\odot$ irradiated with cadmium shield; $\Delta$ irradiated with cadmium and boron shield (solid line, cf. reference [6]).

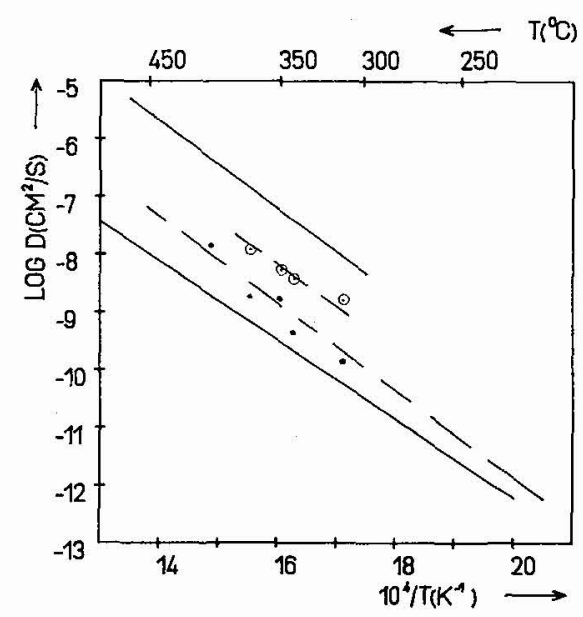

FrG. 3. - Temperature dependence of argon diffusion in $\mathrm{KBr}$ (points and circles, cf. fig. 2 ; solid lines, cf. references [1] and [7]). 
In contrary to $\mathrm{KCl}$, the argon mobility in $\mathrm{KBr}$ is enhanced by adding the cadmium shield, but the activation energy $(\Delta H=1.55 \mathrm{eV})$ remains the same. The values presented here, correspond well with a previous result [7] (cf. upper solid line in figure 3), when considering the strong reduction of the thermal neutron flux by a cadmium shield $\left(\varphi_{\mathrm{th}}=10^{-2} \varphi_{\mathrm{f}}\right)$. The $D$-values also show a good agreement with earlier work on alkaline halides irradiated in the research reactor FRM (München) whith $\varphi_{\text {th }} \approx 2 . \varphi_{\mathrm{f}}[1]$, cf. the two lower solid lines in figure 3 .

In contrast to the findings in $\mathrm{KCl}$ and $\mathrm{KBr}$, the $D$-values in $\mathrm{KI}$ are independent from the thermal neutron fluence, figure 4 . They correspond well with earlier data [8], the Arrhenius plot of which is represented by the solid line in figure 4 .

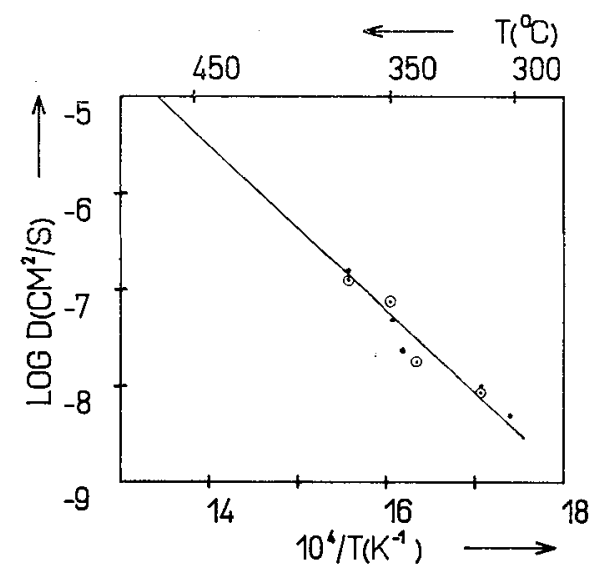

FlG. 4. - Temperature dependence of argon diffusion in KI (points and circles, cf. fig. 2 ; solid line, cf. reference [4]).

Discussion. - According to the trapping diffusion model of Norgett and Lidiard [2] the measured diffusion coefficient $D_{\text {app }}$ can be interpreted by the assumption of a predominant interaction of the rare gas with irradiation defects. It, thus, follows :

$$
D_{\mathrm{app}}=\frac{D k}{c_{\mathrm{T}}} \text {. }
$$

$k=k_{0} \exp \left(-\Delta H_{\mathrm{b}} / k T\right)$ represents the equilibrium constant for the reaction of the rare gas with the irradiation defects, $\Delta H_{\mathrm{b}}$ the binding energy of the gas to the trap, $D=D_{0} \exp \left(-\Delta H_{\mathrm{m}} / k T\right)$ the diffusion coefficient of undisturbed interstitial diffusion, $\Delta H_{\mathrm{m}}$ the migration energy of the rare gas and $c_{\mathrm{T}}$ the concentration of the irradiation defects.

The permanent increase of the activation energy with thermal neutron dose for $\mathrm{KCl} / \mathrm{Ar}$ can be explained by a variation of $k$ in equation (1), since an increase of $c_{\mathrm{T}}$ would only lead to a parallel shift of $D_{\text {eff }}$ in the Arrhenius plot. Thus, thermal neutrons seem to alter the structure of the irradiation defects resulting in a decrease of the binding energy $\Delta H_{b}$.
For $\mathrm{KBr} / \mathrm{Ar}$, however, it has to be assumed according to equation (1) that $c_{\mathrm{T}}$ increases with the thermal neutron dose, since the binding energy of the rare gas remains constant. In this case thermal neutrons may produce additional irradiation defects similar to those induced by fission neutrons.

For $\mathrm{KI} / \mathrm{Ar}, c_{\mathrm{T}}$ as well as $k$ are not influenced by thermal neutrons.

On the basis of this interpretation the following questions are now to be treated :

1) How do thermal neutrons cause the transformation of the fission neutron induced irradiation defects in $\mathrm{KCl}$ ?

2) Which new defects do they produce in $\mathrm{KBr}$ ?

3) Why do thermal neutrons not change the irradiation defects in KI ?

First one has to consider the fission induced defects in the different systems. From the typical data for these defects, summarized in table II, we can see that the production rate $P$ of the primary atoms in the three systems is very similar. However, the differences in primary energies and development of the cascades may lead to a different arrangement of primary defects. Comparing the corresponding median ranges from the stopping power relation of Biersack [10] one may conclude that the extension of the collision cascades increases with decreasing weight of the primary atom in the sequence : $\mathrm{I}<\mathrm{Br}<\mathrm{K} \leqslant \mathrm{Cl}$, cf. table II.

\section{TABLE II}

Data on energy deposition by fission and thermal neutron induced recoils

\begin{tabular}{|c|c|c|c|c|}
\hline System & $\begin{array}{c}P(1) \\
{\left[10^{10} \mathrm{~cm}^{-3} \mathrm{~s}^{-1}\right]}\end{array}$ & $\begin{array}{l}\bar{E}_{\mathrm{p}}(2) \\
{[\mathrm{keV}]}\end{array}$ & $\begin{array}{c}R(3) \\
{[\AA]}\end{array}$ & $\begin{array}{c}\bar{E}\left({ }^{4}\right) \\
{\left[\mathrm{eV} \cdot \mathrm{cm}^{-3} \mathrm{~s}^{-1}\right]}\end{array}$ \\
\hline $\mathrm{K} / \mathrm{KCl}$ & 3.2 & 58.2 & 1082 & $5.3 \times 10^{14}$ \\
\hline $\mathrm{Cl} / \mathrm{KCl}$ & 3.0 & 64.0 & 1336 & \\
\hline $\mathrm{K} / \mathrm{KBr}$ & 2.78 & 58.2 & 1129 & $5.7 \times 10^{13}$ \\
\hline $\mathrm{Br} / \mathrm{KBr}$ & 4.47 & 29.3 & 337 & \\
\hline K/KI & 1.78 & 58.2 & 1710 & $2.1 \times 10^{13}$ \\
\hline I/KI & 3.88 & 18.6 & 254 & \\
\hline
\end{tabular}

(1) Production rate of primary atoms produced by elastic collision with fission neutrons.

(2) Kinetic energy of the primary atoms calculated for the average fission neutron energy $\vec{E}_{\mathrm{n}}=1.2 \mathrm{MeV}$.

(3) Median range of the primaries calculated with the stopping power relation by Biersack [10].

(4) Total energy of thermal neutron induced recoils in the crystal, cf. table II.

On the other hand one has to discuss the influence of the thermal neutrons on those fast neutron induced collision cascades. Neutron capture followed by $\beta^{-}$-decay may lead to new elements. Under certain conditions, these dopants can be more efficient for gas trapping than the proper radiation defects [8]. 
Furthermore, the recoil atoms lead to small collision cascades influencing the fission neutron induced defects. Besides by elastic collisions, the recoils may also dissipate their energy by heating the lattice environment. Thus, a low energy recoil in the vicinity of a larger defect zone may provide energy to change the structure of that zone. It is, however, not quite sure whether the distances between displaced atoms on interstitial sites and the vacancies are larger for high energetic than for low energy recoils, thus, decreasing the chance of recombination. The greater number of defects in a high energy cascade can on the contrary lead to agglomeration in clusters, bubbles or voids.

Third, an influence of the nuclear heating of the different wrapping materials ( $\mathrm{Cd}$ or $\mathrm{B}$ ) on the thermal annealing of the samples cannot a priori be excluded. However, since this effect should operate in all three systems, the observed differences in rare gas diffusion require differences of the primary defects and their annealing behaviour, nevertheless.

In order to evaluate the influence of the different thermal neutron capture processes, the data of the most important reactions in potassium halides are compiled in table III. In the case of $\mathrm{KCl}$ the changes in the ionic charge of the recoil atoms or the doping with nucleogenic alien atoms are too small to explain the differences in binding energies of the rare gas. The storage time after irradiation did not exhibit any influence on the gas release, $i$. e. the increase of the neutral ${ }^{38} \mathrm{Ar}$, the divalent ${ }^{42} \mathrm{Ca}^{2+}$ and the monovalent ${ }^{35} \mathrm{Cl}^{-}$does not change the argon diffusion behaviour. It seems to be rather the conditions during irradiation which lead to the observed deviation of the rare gas kinetics in $\mathrm{KCl}$. Thus, the structural changes of the defects are connected to the energy transfer from the thermal neutron induced recoils.

The higher energetic ${ }^{35} \mathrm{~S}$ recoils can be expected to produce cascades not too different from those induced by elastic scattering of fast neutrons and, thus, should increase the trap concentration $c_{\mathrm{T}}$.

The energy of the $(n, y)$-recoils is much smaller, mostly below $1 \mathrm{keV}$, and, thus, gives rise to small cascades and heating of the lattice. These effects can in particular be expected for $\mathrm{KCl}$ since the absorbed energy $\bar{E}$ is about one order of magnitude higher than for the other two systems, cf. table II. There are also significant contributions from $\beta^{-}$-recoil, cf. table III. Furthermore, the larger extension of the fission neutron induced defects in $\mathrm{KCl}$ provides a greater chance of overlap by a low energy cascade. These arguments may lead to the conclusion, that in $\mathrm{KCl}$ thermal neutron capture favours the annealing processes.

The same does not hold for $\mathrm{KBr}$. The defect zones stemming from elastic scattering of fast neutrons should be denser and less extended than in the case of $\mathrm{KCl}$. A high degree of recombination and aggregation of defects can be expected, leading to a smaller number of permanent defects. The $(n, \gamma)$-induced recoils are less frequent than in $\mathrm{KCl}$, cf. table III, and the energy delivered to the lattice is lower. Consequently, annealing effects should not play the same role in $\mathrm{KBr}$. Compared to the number of stable defects in the high energetic cascades as calculated via the Kinchin-Pease-model, the thermal neutron induced recoils increase $c_{\mathrm{T}}$ by less than $1 \%$. Thus, the observed deviation in rare gas mobility by more than $100 \%$, cf. figure 3 , cannot be explained in a simple manner via additional damage from $(\mathrm{n}, \gamma)$-processes. Otherwise one has to assume that the latter defects possess a much higher chance of survival from recombination and thermal annealing than those in the high energy cascades.

Also the nuclear doping by ${ }^{42} \mathrm{Ca}$, cf. table III, and the creation of cation vacancies by that divalent impurity [8], cannot explain the observed decrease in rare gas mobility, since the concentration of ${ }^{42} \mathrm{Ca}$ is by several orders of magnitude smaller than that of the general impurities. This could be established via measurements of ionic conductivity in neutron irradiated $\mathrm{KBr}[8]$. The conductivity which is proportional to the cation vacancy concentration, was the same for irradiated and non irradiated samples after a certain thermal treatment.

In $\mathrm{KI}$ the contribution from $(\mathrm{n}, \gamma)$-processes is

TABLE III

Nuclear chemical changes in potassium halides during and after reactor irradiation

\begin{tabular}{|c|c|c|c|c|c|}
\hline \multicolumn{4}{|c|}{ Cross } & \multicolumn{2}{|c|}{$\beta^{-}$-decay } \\
\hline Nuclear reaction & $\begin{array}{l}\text { section } \\
\text { [barn] }\end{array}$ & $\begin{array}{c}E_{\mathrm{R}}(\mathrm{Max}) \\
{[\mathrm{keV}]}\end{array}$ & $\begin{array}{c}E_{\mathrm{R}}^{\beta^{-}}(\operatorname{Max}) \\
{[\mathrm{keV}]}\end{array}$ & $\begin{array}{l}\text { Change } \\
\text { of charge }\end{array}$ & $\underline{T_{1 / 2}}$ \\
\hline${ }^{39} \mathrm{~K}(\mathrm{n}, \gamma){ }^{40} \mathrm{~K}$ & 1.96 & 0.817 & - & - & $1.28 \times 10^{9} \mathrm{a}$ \\
\hline${ }^{41} \mathrm{~K}(\mathrm{n}, \gamma){ }^{42} \mathrm{~K} \stackrel{\beta^{-42}}{\rightarrow} \mathrm{Ca}$ & 1.46 & 0.728 & 0.637 & $+1 \rightarrow+2$ & $12.5 \mathrm{~h}$ \\
\hline${ }^{35} \mathrm{Cl}(\mathrm{n}, \mathrm{p}){ }^{35} \mathrm{~S} \overrightarrow{\beta-}^{35} \mathrm{Cl}$ & 0.30 & 18.14 & 0.0036 & $-2 \rightarrow-1$ & $88 \mathrm{~d}$ \\
\hline${ }^{35} \mathrm{Cl}(\mathrm{n}, \gamma){ }^{36} \mathrm{Cl}$ & 44 & 1.097 & - & - & $3.0 \times 10^{5} \mathrm{a}$ \\
\hline${ }^{37} \mathrm{Cl}(\mathrm{n}, \gamma){ }^{38} \mathrm{Cl} \stackrel{\beta \rightarrow-38}{\rightarrow} \mathrm{Ar}$ & 0.40 & 0.529 & 1.367 & $-1 \rightarrow 0$ & $38 \min$ \\
\hline${ }^{79} \mathrm{Br}(\mathrm{n}, \gamma){ }^{80} \mathrm{Br} \stackrel{\beta-80}{\rightarrow} \mathrm{Kr}$ & $2.6+8.5$ & 0.417 & 0.109 & $-1 \rightarrow 0$ & $17.6 \mathrm{~min}$ \\
\hline${ }^{81} \mathrm{Br}(\mathrm{n}, \gamma){ }^{82} \mathrm{Br} \overrightarrow{\beta-82} \mathrm{Kr}$ & $2.43+0.26$ & 0.378 & 0.006 & $-1 \rightarrow 0$ & $35.3 \mathrm{~h}$ \\
\hline${ }^{127} \mathrm{I}(\mathrm{n}, \gamma){ }^{128} \mathrm{I} \stackrel{\beta-128}{\rightarrow} \mathrm{Xe}$ & 6.2 & 0.094 & 0.076 & $-1 \rightarrow 0$ & $25 \min$ \\
\hline
\end{tabular}


by far too small to provoke any effect on the defect arrangement stemming from the high energy collision cascades.

In conclusion it can be stated that the effects of the reactor neutron spectrum on the kind and concentration of defects active in rare gas trapping can qualitatively be unders:ood for $\mathrm{KCl}$ and $\mathrm{KI}$. With respect to the results in $\mathrm{KBr}$ the explanation is less satisfactory. Thus, a more detailed study of arrange- ment and annealing properties of the radiation induced defects is needed. As a first approach, the primary defect situation shall be evaluated by computer simulation of low and high energy collision cascades in alkaline halides via the binary collision program Marlowe which has already successfully contributed to problems of radiation damage in ionic complex compounds, cf. e. g. [11]. The results will be reported in a parallel publication in this journal [12].

\section{References}

[1] Beutin, B., Felix, F. W., Meier, K. and Müller, M., AED-CONF-1973-407-023.

[2] Norgett, M. J. and Lidiard, A. B., Phil. Mag. 18 (1968) 1193.

[3] LAGERWALl, T. and ZIMEN, K. E., Report HMI-B-25 (1963).

[4] MüLxLeR, M. and FeLIX, F. W., Z. Naturforschg. 25a (1970) 1892.

[5] Felix, F. W., Phys. Status Solidi b 27 (1968) 529.

[6] Felix, F. W., MeIER, K. and MülleR, M., Z. Naturforschg. 29a (1974) 1299.
[7] RICHTRR, A. H. K. and Zimen, K. E., Z. Naturforschg. 20a (1965) 667.

[8] Feltx, F. W. and Müller, M., Phys. Status Solidi b 46 (1971) 265.

[9] MÉrER, K., Thesis D83, Freie Universität Berlin 1970.

[10] BIERSACK, J., Report HMI-B-37 (1964).

[11] Robinson, M. T., Rössler, K. and Torrens, I. M., J. Chem. Phys. 60 (1974) 680.

[12] Rössler, K., Felix, F. W. and Müller, M., J. Physique Collog. 37 (1976) C7, this issue. 